\title{
Electrical Stimulation of the Midbrain for Hearing Restoration: Insight into the Functional Organization of the Human Central Auditory System
}

\author{
Hubert H. Lim, ${ }^{1}$ Thomas Lenarz, ${ }^{1}$ Gert Joseph, ${ }^{1}$ Rolf-Dieter Battmer, ${ }^{1}$ Amir Samii, ${ }^{2}$ Madjid Samii, ${ }^{2}$ James F. Patrick, ${ }^{3}$ \\ and Minoo Lenarz ${ }^{1}$ \\ ${ }^{1}$ Otorhinolaryngology Department, Hannover Medical University, 30625 Hannover, Germany, ${ }^{2}$ Neurosurgery Department, International Neuroscience \\ Institute, 30625 Hannover, Germany, and ${ }^{3}$ Cochlear Limited, Lane Cove, New South Wales 2066, Australia
}

The cochlear implant can restore speech perception in patients with sensorineural hearing loss. However, it is ineffective for those without an implantable cochlea or a functional auditory nerve. These patients can be implanted with the auditory brainstem implant (ABI), which stimulates the surface of the cochlear nucleus. Unfortunately, the ABI has achieved limited success in its main patient group [i.e., those with neurofibromatosis type 2 (NF2)] and requires a difficult surgical procedure. These limitations have motivated us to develop a new hearing prosthesis that stimulates the midbrain with a penetrating electrode array. We recently implanted three patients with the auditory midbrain implant (AMI), and it has proven to be safe with minimal movement over time. The AMI provides loudness, pitch, temporal, and directional cues, features that have shown to be important for speech perception and more complex sound processing. Thus far, all three patients obtain enhancements in lip reading capabilities and environmental awareness and some improvements in speech perception comparable with that of NF2 ABI patients. Considering that our midbrain target is more surgically exposable than the cochlear nucleus, this argues for the use of the AMI as an alternative to the ABI. Fortunately, we were able to stimulate different midbrain regions in our patients and investigate the functional organization of the human central auditory system. These findings provide some insight into how we may need to stimulate the midbrain to improve hearing performance with the AMI.

Key words: auditory brainstem implant; auditory midbrain implant; auditory pathways; deep brain stimulation; inferior colliculus; NF2

\section{Introduction}

More than 100,000 patients worldwide suffering from severe to profound hearing loss have been implanted with a cochlear implant (CI). The CI converts acoustic sound into electrical stimulation patterns that are transmitted to the cochlea to excite the remaining auditory nerve fibers. Many CI patients routinely converse over the telephone (Adams et al., 2004). Thus, they achieve intelligible speech perception without lip-reading cues. It is no wonder that the $\mathrm{CI}$ has become one of the success stories of the neural prosthetic field.

Unfortunately, not all deaf patients are equipped with a functional auditory nerve or implantable cochlea required for a CI. For these patients, there exists the auditory brainstem implant (ABI), which stimulates the surface of the cochlear nucleus. The initial motivation for the $\mathrm{ABI}$ was to restore hearing in neurofibromatosis type II (NF2) patients [ 1 in 40,000 births (Evans et

Received July 9, 2007; revised 0ct. 14, 2007; accepted 0ct. 19, 2007.

This work was supported by Cochlear Limited. We thank Urte Rost for performing hearing tests; Dr. Joerg Pesch for technical assistance; Drs. Hans-Joachim Kretschmann and Martin Bokemeyer for CT-MRI reconstructions and identification of the AMI array location in each patient; and Frank Risi and Peter Gibson for AMI development.

Correspondence should be addressed to Dr. Hubert H. Lim, Medizinische Hochschule Hannover, HNO Klinik, Carl-Neuberg-Strasse 1 (Gebaeude K5, Ebene 1, Raum 4010), 30625 Hannover, Germany. E-mail: hubertlim@aol.com.

DOI:10.1523/JNEUROSCI.3123-07.2007

Copyright $\odot 2007$ Society for Neuroscience 0270-6474/07/2713541-11\$15.00/0 al., 1992)], who usually develop bilateral acoustic neuromas and require tumor removal that leads to complete deafness. Because the cochlear nucleus is approached during tumor surgery, it was selected as the implant site. However, hearing performance has been limited and array placement is complicated by brain distortions caused by the tumor, a visually obscured approach, and the risk of damaging critical brainstem structures and cranial nerves (Brackmann et al., 1993; Otto et al., 2002). Furthermore, it is not uncommon for the electrode array to move postoperatively. Recently, the $\mathrm{ABI}$ has been implanted in nontumor patients who would not benefit from CIs (e.g., such as those with nerve avulsion/aplasia and cochlear ossification). Surprisingly, some of these patients achieve performance levels comparable with CI patients, suggesting that the limited performance of NF2 ABI patients may be attributed to some tumor-related damage within the cochlear nucleus (Colletti and Shannon, 2005). Thus, a site proximal to this damaged region may be better for an auditory prosthesis.

Our animal studies (Lim and Anderson, 2003, 2006; Lenarz et al., 2006a) have shown that the inferior colliculus (IC), particularly its central nucleus (ICC), has potential as a new site for an auditory prosthesis. In particular, ICC stimulation achieves lower thresholds, greater dynamic ranges, and more localized, frequency-specific cortical activation than CI stimulation. The IC also receives inputs from almost all brainstem pathways projecting to higher perceptual centers (Casseday et al., 2002). Thus, it 
Table 1. Patient summary

\begin{tabular}{|c|c|c|c|}
\hline Name & AMI-1 & AMI-2 & AMI-3 \\
\hline Gender & Female & Male & Female \\
\hline Age (year) & 71 & 28 & 42 \\
\hline Hearing status $^{a}$ & Residual right ear & Hearing aid left ear & None \\
\hline Tinnitus $^{a}$ & Sometimes & Always & Always \\
\hline Implant side & Left & Right & Right \\
\hline Implant date & 07/04/06 & 08/08/06 & $10 / 25 / 06$ \\
\hline Turn on date & $08 / 07 / 06$ & $09 / 11 / 06$ & $12 / 13 / 06$ \\
\hline Side effect sites & $12-20$ & $1-9,20$ & $12-20$ \\
\hline Side effects & $\begin{array}{l}\text { Dizziness, contralateral facial twitch, head/chest } \\
\text { sensations and warmness }\end{array}$ & $\begin{array}{l}\text { Paresthesia in contralateral upper body and face, } \\
\text { coldness in contra face }\end{array}$ & Paresthesia in contralateral thigh, leg, and foot \\
\hline Active sites $^{b}$ & $1,2,4-9$ & $10,11,13-19$ & $1-9$ \\
\hline Processor ${ }^{a, c}$ & $\mathrm{ACE}, 6-8$ maxima & SPEAK, 8 maxima & SPEAK, 6 maxima \\
\hline
\end{tabular}

${ }^{a}$ For additional details, see Materials and Methods.

${ }^{b} 0$ ther sites not listed either caused unpleasant sounds (i.e., a low-pitch screechy sound or sensation that was uncomfortable but difficult to describe) or were shorted to other active sites and thus were not used for daily stimulation. ${ }^{`} \mathrm{MP} 1+2,250 \mathrm{pps}, 100 \mu \mathrm{s} /$ phase pulses. Parameters were selected based on various psychophysical tests and device limitations that will be further discussed in a separate publication. Further details on the processor are provided by Patrick et al. (2006).

should provide direct access to a more complete set of pathways necessary for complex processing and binaural percepts than occurs in the cochlear nucleus or cochlea for the ABI or CI, respectively. Initially, the motivation for an auditory midbrain implant (AMI) will be to restore hearing in NF2 patients because the AMI can be implanted during their tumor removal surgery with minimal added risk (Samii et al., 2007). If the AMI outperforms the $\mathrm{ABI}$ and $\mathrm{CI}$, then it may serve as an alternative hearing solution for the more general deaf community provided that surgical risks are minimized possibly through stereotactic procedures.

We have begun clinical trials in which three NF2 patients have been implanted with the AMI. The goal of this study has been (1) to demonstrate the safety and evaluate the efficacy of the AMI for hearing restoration and (2) to better understand the functional organization of the human central auditory system, which will help us improve future AMI designs and stimulation strategies. We will discuss findings associated with level coding, tonotopy, temporal coding, and sound localization pathways within the human midbrain.

\section{Materials and Methods \\ Patients and surgery}

Three patients have been implanted with the AMI. Table 1 summarizes demographic and implant-related information for each patient, and Figure $1 A$ provides a description of the AMI array and system. All three patients were diagnosed with the NF2 disease and required acoustic neuroma removal on a deafened side. The tumor was first removed using a modified lateral suboccipital approach (semi-sitting position), and then the surface of the IC on the same side was exposed through a lateral supracerebellar infratentorial approach with minimal added risk for array implantation. Details of this approach have been presented previously (Samii et al., 2007). Surgical results from these patients will be discussed in a separate publication. This study was conducted in accordance with ISO 14155 (International Standard for Clinical Investigation of Medical Devices) and follows the Good Clinical Practice guidelines. Medical Ethics Committee and Competent Authority written approvals according to national laws were obtained, and the patients signed informed consent forms before AMI implantation and testing.

AMI-1 has residual tonal hearing in the right ear $(30-50 \mathrm{~dB}$ HL for $0.125-1 \mathrm{kHz} ;>70 \mathrm{~dB}$ HL for $>1 \mathrm{kHz}$ ). However, she scored poorly on our standard speech test used to assess implant eligibility $(<10 \%$ at 110 dB HL for Freiburger monosyllable word test; CI criteria, $<30 \%$ at $65 \mathrm{~dB}$ $\mathrm{HL}$ ), indicating her inability to benefit from hearing aids and consistent with a neural hearing loss. Thus, she was implanted on the left side after the tumor was removed. AMI-2 had residual tonal hearing in the left ear ( $>90 \mathrm{~dB} \mathrm{HL}$ ) and could obtain some improvements in lip-reading capabilities using a hearing aid. However, he was experiencing rapid deterio- ration in his hearing, which justified implantation of the AMI on the right side during tumor removal surgery. AMI-3 was completely deaf for 6 years and had been implanted previously two times with the ABI on the left side. In both cases, the ABI became postoperatively displaced into the fourth ventricle because of the enlarged facial recess created by the large tumor that was removed. AMI-3 was then implanted with the AMI during removal of a residual acoustic neuroma on the right side

All patients have tinnitus, which was present before and after surgery. Although patients expressed that AMI stimulation could alter their tinnitus, there appears to be other factors that also affect the tinnitus to account for its variability on a daily basis (e.g., tinnitus in AMI-1 is not always present). During psychophysical tests, we instructed the patients to ignore the tinnitus and focus on the test stimulus.

\section{Identification of array placement}

Three-dimensional magnetic resonance imaging (MRI) slices $(0.9 \mathrm{~mm}$, $24.3 \times 24.3 \mathrm{~cm}$ field of view, $512 \times 384$ matrix) were obtained from each patient before AMI implantation using a 1.5 Tesla magnet (Allegra; Siemens, Erlangen, Germany) with a T1-magnetization-prepared rapidacquisition gradient echo sequence (6.2 repetition time, 3.1 echo time). Accurate MRI images of the midbrain could not be obtained after AMI implantation because of the distortion caused by the electrode array (Fig. $1 A)$ and telemetry interface magnet. Instead, computed tomography (CT) images (Light Speed VFX; GE Medical Systems, Milwaukee, WI) using a multi-slice helical data acquisition method ( 0.625 collimation, $120 \mathrm{kV}, 250 \mathrm{~mA}, 512 \times 512$ matrix) were obtained in each patient at least 6 weeks after AMI implantation to avoid brain distortions caused by the surgery. The MRI data were then semiautomatically reoriented and fused to the CT data (Advantage Fusion 1.1.1; GE Medical Systems) with an accuracy of $<1 \mathrm{~mm}$. The landmarks used for the CT-MRI reconstructions were the nasion, top of the dens axis, and the internal occipital protuberance. For identification of the array location within different midbrain structures, $1 \mathrm{~mm}$ slices of the fused images were compared with fixed human brain slices of similar dimension that were taken from the anatomical brain collection at the Department of Neuroanatomy in Hannover Medical University (Kretschmann and Weinrich, 1992). The alignment of the array with respect to the ICC layers were determined by comparing the fused images and fixed slices with stained midbrain sections presented by Geniec and Morest (1971).

\section{Psychophysical tests}

The tests were performed using 250 pulses per second (pps) and/or 100 $\mu \mathrm{s} /$ phase biphasic (cathodic-leading), monopolar pulses that were presented on a selected site (of the active sites listed in Table 1) and directly controlled using Custom Sound or Custom Sound EP software (Cochlear, Ltd., Lane Cove, New South Wales, Australia). The interphase gap duration of each biphasic pulse varied across tests depending on which program was used. Unless otherwise specified, the gap was $7 \mu \mathrm{s}$. The 
A

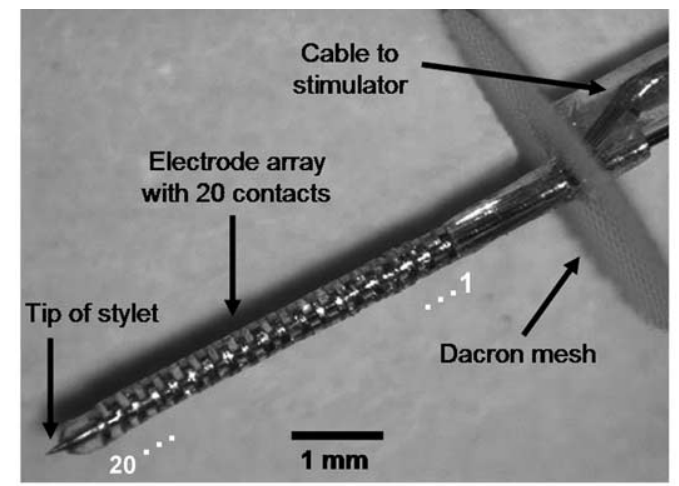

B

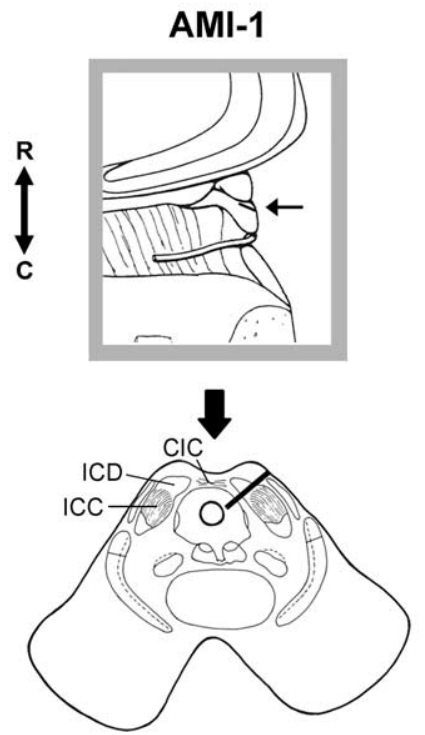

AMI-1

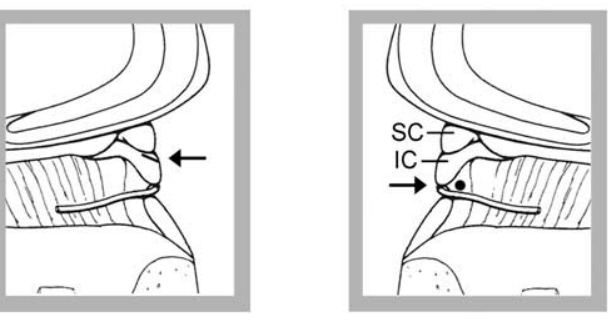

AMI-2

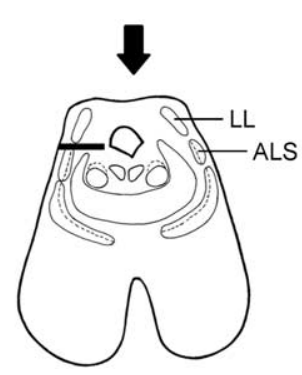

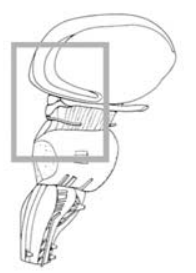

AMI-3
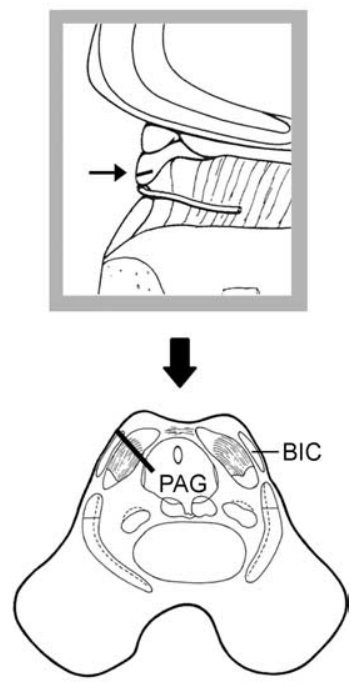

Figure 1. AMI array design and placement within each patient. $\boldsymbol{A}$, Image of the AMI array. The AMI system consists of similar components (i.e., microphone, processor, telemetry interface, and current stimulator) as the Nucleus Freedom $\mathrm{Cl}$ systems (C0chlear $\mathrm{Ltd}$.). A review of the Nucleus $\mathrm{Cl}$ systems has been provided by Patrick et al. (2006). The array is $6.2 \mathrm{~mm}$ long with a diameter of $0.4 \mathrm{~mm}$. It consists of 20 platinum ring electrodes linearly spaced at an interval of $200 \mu \mathrm{m}$. Each site has a thickness of $100 \mu \mathrm{m}$ (surface area of $\sim 126,000 \mu \mathrm{m}^{2}$ ). A stainless steel stylet is positioned through the axial center of the silicone carrier to enable insertion of the array into the brain and is removed after placement. Additional details on the AMI electrode array have been provided previously (Lenarz et al., 2006b). For our analyses and plots, we ordered the array sites from 1 to 20 , with 20 being the tip site. $\boldsymbol{B}$, Parasagittal (top) and axial (bottom) sections showing the location and orientation of the array within the midbrain of each patient. Arrow in parasagittal section points to the caudorostral location of the array and the corresponding axial section below. The black line (or dot for AMI-2) representing the array in each section corresponds to the trajectory of the array across several superimposed CT-MRI slices. For more details, see Materials and Methods, Identification of array placement. ALS, Anterolateral system; BIC, brachium of IC; C, caudal; CIC, commissure of IC; D, dorsal; ICD, inferior colliculus dorsal cortex; LL, lateral lemniscus; $P A G$, periaqueductal gray; $R$, rostral; $S C$, superior colliculus; $V$, ventral.

monopolar $(\mathrm{MP} 1+2)$ return path was through both the plate electrode attached to the receiver-stimulator implanted in a bony bed in the skull behind the ear (temporoparietal area) and a ball electrode placed within the temporalis muscle. The stimulus parameters were selected based on various psychophysical tests, and those results will be presented in a separate publication. Briefly, 250 pps was high enough to avoid noticeable rate pitch effects (i.e., increasing rates up to 2400 pps did not noticeably increase the pitch from that at 250 pps) and the lowest rate available for daily stimulation to minimize adaptive effects. These parameters also achieved the largest drop in thresholds in which using longer pulse widths and higher pulse rates (thus greater total charge) did not decrease thresholds by much more, whereas using shorter pulse widths and slower pulse rates substantially increased threshold levels. This was important for identifying stimuli that required less total charge (thus more energy efficient activation) yet was still reasonably within the compliance voltage limits of the stimulator and the safety limit for CNS stimulation. For the sound localization and pitch ordering tests described below, all sites were loudness balanced by sequentially stimulating the different sites and adjusting the levels until the patient expressed that all the stimulated sites elicited the same loudness sensation.

Threshold and comfortable levels

Threshold (T) and comfortable (C) levels were measured for each active site, which was electrically stimulated with a pulse train with a duration of $500 \mathrm{~ms}$ that was continuously repeated at $1 \mathrm{~Hz}$. The current level was first increased to elicit a moderate perceived sound level and then decreased until the patient could no longer hear the stimulus, which was taken as T level. C level corresponded to a comfortable loudness obtained when increasing the current from $\mathrm{T}$ level. These measurements were repeated several times for each testing session until the patients provided consistent $\mathrm{T}$ and $\mathrm{C}$ levels. The interphase gap was $8 \mu$ s for AMI-1 (ACE setup) and $45 \mu$ s for the other two patients (SPEAK setup).

\section{Sound localization}

The patients were presented with a pulse train delivered to a selected site that consisted of a $500 \mathrm{~ms}$ burst repeated at $1 \mathrm{~Hz}$ for $3 \mathrm{~s}$ at $\mathrm{C}$ level. The patients were instructed to then point to a direction (i.e., azimuth angles of $-135^{\circ},-90^{\circ}$, $-45^{\circ}, 0^{\circ}, 45^{\circ}, 90^{\circ}, 135^{\circ}$, and $180^{\circ}$ as initially demonstrated by the experimenter) from where they believed the perceived sound originated. A negative direction corresponded to a contralateral perceived sound, a positive direction to an ipsilateral sound, $0^{\circ}$ for a sound coming from both directions or in front, and $180^{\circ}$ for a sound coming from behind. We also included intermediate directions (i.e., $-135^{\circ}$, $-45^{\circ}, 45^{\circ}$, and $135^{\circ}$ ) because the patients occasionally expressed that the perceived sounds did not always appear to originate directly from the front or either side. Finer intermediate steps were not used because the patients could not further determine whether the sounds originated closer to the front or to the sides but only perceived the sounds to come from some diagonal location. These measurements were randomly repeated three times and averaged for each site.

\section{Pitch ordering methods}

Pitch ranking (two-alternative forced choice).

Two sites were sequentially stimulated with pulse trains at Clevel each for $500 \mathrm{~ms}$ with an interstimulus gap of $500 \mathrm{~ms}$ ( $8 \mu$ s interphase gap for AMI-1, $45 \mu$ s gap for AMI-2 and AMI-3). The patient was then asked to select the stimulated site that elicited a higher pitch. After randomly stimulating all pairwise combinations (including pairs with different ordering, e.g., $1-2$ and 2-1 are different pairs) of the active sites (four times each), the total number of times one site had a higher pitch than another site was tabulated in an $N \times N$ matrix, where $N$ corresponds to the number of sites. For example, if there are five sites numbered $1-5$, the first column would correspond to site 1 in which each row would correspond to 1 through 5 . The total number of times site 1 elicited a higher pitch than site 2 would be inserted into the first columnsecond row. The total number of times site 2 elicited a higher pitch than site 3 would be inserted in the second column-third row, and so on. All diagonal values were set to 0 . Then the sum across each column was calculated in which a higher score indicated that the site corresponding to 
that column had a higher pitch. Finally, we divided that score by the maximum score possible and multiplied it by 100 to obtain a value from 0 to 100 in which 0 corresponds to the lowest pitch and 100 to the highest pitch.

Pitch scaling. A given site was stimulated with a $500 \mathrm{~ms}$ pulse train repeated at $1 \mathrm{~Hz}$ for $3 \mathrm{~s}$ at $\mathrm{C}$ level $(8 \mu \mathrm{s}$ interphase gap for AMI-1, $45 \mu \mathrm{s}$ gap for AMI-2 and AMI-3). The patient was then asked to scale the pitch from 0 to 50 (integers) in which 0 corresponded to the lowest pitch perceived across all the stimulated sites and 50 corresponded to the highest pitch. These measurements were randomly repeated 10 times for each site. The average pitch value for each site was multiplied by 2 to obtain a value from 0 to 100 , which enabled comparison with the pitch ranking results.

Absolute pitch. Each site was electrically stimulated with a 3-s-duration pulse train at $\mathrm{C}$ level, and the patient was asked to scale the perceived pitch based on our environmental scale $(0-5)$ presented in Figure 5. The patients were instructed to select an environmental sound on our pitch scale that most resembled the pitch level of the perceived sound. These measurements were randomly repeated across sites for a total of five times for each site.

\section{Loudness growth functions}

A 500-ms-duration pulse train was presented on a selected site at a given current level, and the patient was asked to scale the loudness based on a $0-50$ scale as presented in Figure 6. These measurements were repeated five times for each site and level in a randomized manner and averaged to obtain loudness growth functions.

\section{Temporal resolution}

Continuous pulse trains were presented from 10 up to $250 \mathrm{pps}$ ( $10 \mathrm{pps}$ steps) at $\mathrm{C}$ level, and the patients indicated when the individual pulses began to sound continuous. At very low rates, the individual pulses could be distinctly heard. At higher rates, the pulses appeared as a "buzzing" that then began to sound continuous. We asked the patients to indicate when the sound initially sounded more continuous than buzzing. Loudness balancing was difficult to perform across the different sites and pulse rates attributable to limitations in our testing software. Because performance on this test was mostly affected by whether or not the patient could clearly hear the sound rather than the slight variations in loudness around C level, it was sufficient to simply adjust the loudness for each site and pulse rate combination individually.

\section{Speech tests}

Each patient received several days of speech and environmental sound training during the first week the implant was turned on. The patients returned for several days every month so we could adjust their processors, perform various psychophysical tests and training sessions, and assess their speech perception performance. The stimulation parameters and active sites are provided in Table 1. Basically, sound (i.e., live voice or environmental sounds during testing and training, or sounds from daily use) was inputted through a microphone attached to the patient's behind-the-ear processor and processed using standard CI strategies (i.e., ACE or SPEAK) (Nucleus CI system; Cochlear Ltd.) (Patrick et al., 2006). The sound was bandpassed filtered into $N$ number of channels in which $N$ corresponded to the number of active sites. Then $M$ (number of maxima listed in Table 1) channels with the most signal energy were selected, and the envelopes of those bandpassed signals were used to amplitude modulate pulse trains delivered to each of the $M$ selected sites in an interleaved stimulation pattern. The pulse trains consisted of 250 pps, $100 \mu$ s/phase monopolar (MP1+2 as described and used for the psychophysical tests) pulses. ACE uses an interphase gap of $8 \mu \mathrm{s}$, whereas SPEAK uses a gap of $45 \mu \mathrm{s}$. The other main parameters that need to be set are the T/C levels, which we measured as described above using the appropriate ACE or SPEAK setup, and the pitch ordering, which we could approximately obtain with our different pitch test methods. We then manually adjusted the pitch order until the patient indicated that the pitch percepts systematically increased from low to high. Unless large changes were observed in the electrode pitch order, we did not modify the pitch maps at subsequent sessions. This ensured that the patients could become familiarized with their stimulation strategy.

The German speech tests below are similar to those used in our clinic for assessing CI and ABI patients (Strauss-Schier et al., 1995; Rost and Strauss-Schier, 1998; Lenarz et al., 2001). They were performed in live voice under lip reading alone, lip reading plus the AMI, and AMI alone. The difference between lip reading plus AMI and lip reading alone is known as lip-reading enhancement.

\section{Vowel confusion test (closed set)}

Ten monosyllable vowels composed of five long (BIIT, BEET, BAAT, BOOT, BUUT) and five short (BIT, BET, BAT, BOT, BUT) sounds were randomly read to the patient (four times), and he or she was asked to repeat the words as well as point to the them on a sheet that listed all of the words. The chance level is $10 \%$.

\section{Consonant confusion test (closed set)}

Thirteen meaningless consonant words (APA, ABA, AMA, AFA, ASA, ATA, ANA, ADA, AKA, AGA, ALA, ARA, AWA) were randomly read to the patient (four times), and he or she was asked to repeat the words as well as point to them on a sheet that listed all of the words. The chance level is $7.7 \%$.

\section{Freiburger number test (open set)}

This is a standardized open set test in German composed of 20 numbers between 13 and 99 (two to five syllables) that were presented to the patient, and he or she was asked to repeat the numbers. A correct response is equivalent to $5 \%$, and chance level is $<1 \%$.

\section{Speech tracking (modified open set)}

This speech tracking method was derived from De Filippo and Scott (1978). Basically, a story was read to the patient, and he or she was asked to repeat the words of the cited sentences. The number of correct words in 5 min was obtained and divided by 5 to obtain the correct number of words per minute. Chance level is 0 . The story consisted of sentences with different levels of difficulty. Normal hearing subjects tested in our clinic achieve $\sim 85-100$ words per minute (Strauss-Schier et al., 1995).

\section{Results}

\section{Array placement}

Figure 1 provides the location of the implanted AMI array in each patient based on CT-MRI reconstructions. A description of the AMI array is provided in Figure $1 A$. The array was implanted into the left IC of AMI-1. Our intention was to insert the array $45^{\circ}$ off the sagittal plane perpendicular to the IC surface and into the ICC to position the sites within different anatomical layers (Geniec and Morest, 1971), which supposedly correspond to different frequency laminas based on animal studies (Oliver, 2005). The parasagittal section (top) of Figure $1 B$ shows that the array was inserted in the rostral portion of the IC with a caudal-to-rostral rather than a perpendicular orientation relative to the IC surface. The axial section (bottom) shows that the array was inserted through the dorsal cortex of the IC with an $\sim 45^{\circ}$ angle. The end of the array extends into nonauditory regions. As a result, stimulation of deeper sites (sites 12-20) elicited dizziness and sensations in the chest and contralateral face and were not used for daily stimulation. In AMI-2, the array was inserted $\sim 90^{\circ}$ from the sagittal plane below the right IC at the level of the dorsal nucleus of the lateral lemniscus in which fibers ascending into the IC are located. Based on human anatomical data (Geniec and Morest, 1971; Moore, 1987), the sites were positioned near the ventral edge of the lateral lemniscus (and close to nonauditory structures) acting more as surface electrodes. As a result, stimulation of all sites elicited a mixture of auditory and nonauditory sensations, of which the latter consisted of paresthesia and cold sensations in the contralateral face and upper body. Some sites elicited predominantly auditory sensations and could be used for daily 

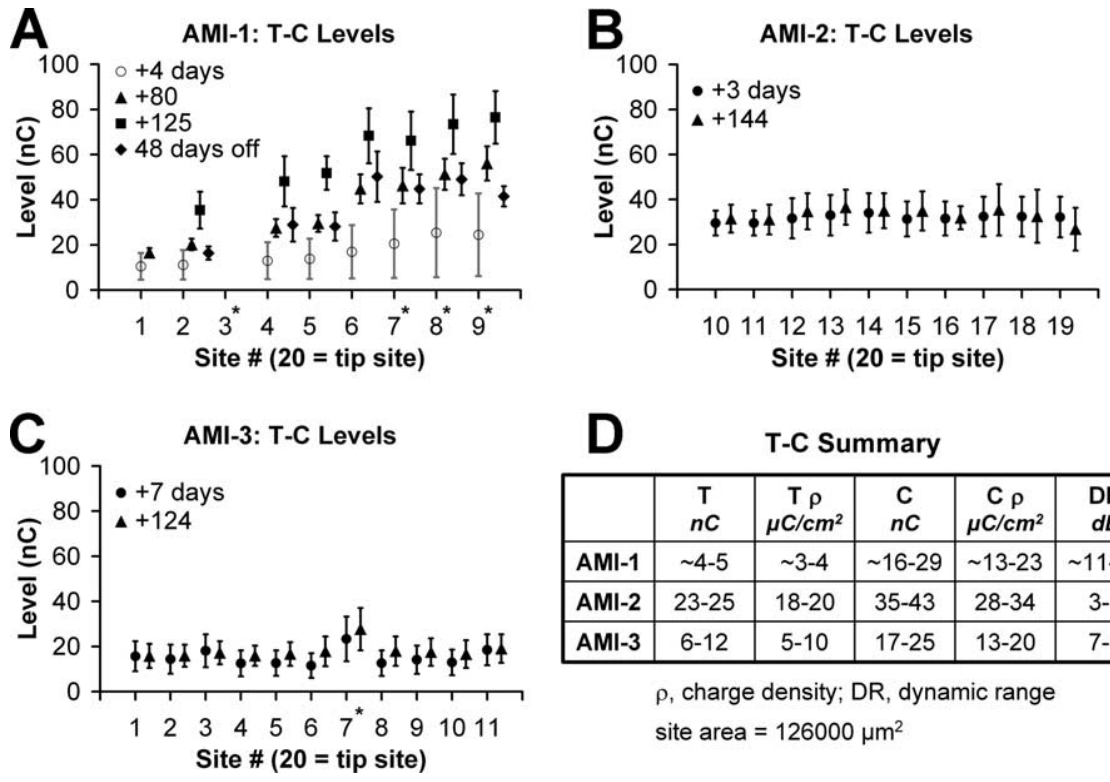

\begin{tabular}{|c|c|c|c|c|c|}
\hline & $\begin{array}{c}\mathrm{T} \\
n c\end{array}$ & $\begin{array}{c}\mathrm{T} \rho \\
\mu \mathrm{C} / \mathrm{cm}^{2}\end{array}$ & $\begin{array}{c}C \\
n C\end{array}$ & $\begin{array}{c}\mathrm{C} \rho \\
\mu \mathrm{C} / \mathrm{cm}^{2}\end{array}$ & $\begin{array}{l}\text { DR } \\
d B\end{array}$ \\
\hline AMI-1 & $\sim 4-5$ & $\sim 3-4$ & $\sim 16-29$ & $\sim 13-23$ & $\sim 11-15$ \\
\hline AMI-2 & 23-25 & $18-20$ & $35-43$ & $28-34$ & $3-5$ \\
\hline AMI-3 & $6-12$ & $5-10$ & $17-25$ & $13-20$ & $7-9$ \\
\hline
\end{tabular}

Figure 2. Tand C levels over time. A, T-C levels (endpoints of bars) for AMI-1 measured for four different time points (symbols) from when the implant was initially turned on. Because of rising levels over time, the implant was turned off for $48 \mathrm{~d}$ (after the $+125 \mathrm{~d}$ measurement) and then T-C levels were measured again. At $+4 \mathrm{~d}$, only the modified T-C levels used for the daily processor rather than the actual measured values were available. Thus, they are labeled with an open symbol and lighter shaded bars. $\boldsymbol{B}, \boldsymbol{C}, \mathrm{T}-\mathrm{C}$ levels for AMI-2 and AMI-3 measured at two different time points and demonstrating stability over time. $\boldsymbol{D}$, Summary of values for each patient only for the values from the first testing session shown in $A-C$ and excluding the shorted sites. Asterisks correspond to sites shorted to other inactive sites. Site 3 for AMI-1 was inactivated because it is shorted to site 9 .

stimulation. The array in AMI-3 was inserted $\sim 45^{\circ}$ from the sagittal plane with a slight caudal-to-rostral orientation relative to the surface of the right IC. The array was inserted into the caudal and dorsomedial portion of the ICC based on anatomical results presented by Geniec and Morest (1971). Sites 12-20 were positioned into deeper nonauditory regions and elicited paresthesia in the contralateral thigh, leg, and foot. Thus, they were turned off for daily stimulation.

From our surgical experience in implanting these three patients, we have improved our methods for placing the array within the ICC. Surgical guidelines and issues as well as a detailed description of the various nonauditory percepts associated with surrounding IC regions will be presented in a separate publication. In brief, no patients experienced any pain or adverse functional effects attributable to AMI implantation or stimulation. They experienced some uncomfortable side effects to AMI stimulation (Table 1) that could be avoided by inactivating certain sites.

\section{Threshold and comfortable levels}

To program the AMI processor, the $\mathrm{T}$ and $\mathrm{C}$ levels must be determined for each active site. Occasionally, the $\mathrm{T}$ and $\mathrm{C}$ levels are slightly adjusted for daily stimulation to accommodate loudness summation effects across sites. Generally, as we increased the current level, the patients perceived auditory sensations that increased in loudness. All patients described the percepts as tonal in nature, but some sites elicited a broad spectral percept with multiple pitches, which occurred most frequently in AMI-2 whose sites appear to be located outside the IC acting as surface electrodes. AMI-3 stated that some sites during the first stimulation session elicited double tones in which the higher pitch component resembled a ringing bell that died out within a few seconds. These double tone percepts were not present 1 month later. The patients also described the sounds as having an electronic quality mixed in with the tonal percept. AMI-2 stated that the auditory sensations reminded him of the electronic sounds made by his cellular phone. Some sites produced unpleasant sounds (i.e., a low pitch screechy sound or a sensation that was uncomfortable but difficult to describe) and were not used for daily stimulation. There were also directional percepts that differed across patients and are discussed in the next section.

Figure 2 summarizes the $\mathrm{T}$ and $\mathrm{C}$ levels measured for different sites in each patient over time. The asterisks correspond to sites that were shorted to other sites, and only one electrode from each shorted group was used for stimulation. The activation levels and current spread were greater for these shorted sites because current could flow through multiple locations. Unless the shorted sites elicited mixed pitch percepts or extremely high thresholds, we still used them as active sites for daily stimulation.

The activation levels for AMI-1 (Fig. $2 A$ ) were initially some of the lowest from the three patients. Note that the $\mathrm{T}$ and $\mathrm{C}$ levels presented in Figure $1 A$ for $+4 \mathrm{~d}$ (from when implant was first turned on) are approximate values. The actual measured values were unavailable, and the modified values used for daily stimulation are shown. Over time, the T and C levels for AMI-1 continued to rise, reaching the compliance voltage of our stimulator (at $+125 \mathrm{~d}$ ). Because of this rise in levels, we turned off the processor for $48 \mathrm{~d}$ to assess whether levels would return to usable levels. The activation levels decreased dramatically but not completely to the initial values. It is not clear as to what may be causing these adaptive effects. One hypothesis is that the stimulation rates and patterns are overdriving the neurons located within the dorsal IC region, which receives a large number of projections from auditory and nonauditory centers (Winer, 2005) and may be designed for adapting to different stimuli (Perez-Gonzalez et al., 2005). We are currently investigating various stimulation strategies for effective and stable activation. The other two patients exhibited stable activation levels over time (Fig. $2 \mathrm{~B}, \mathrm{C}$ ), suggesting that location of stimulation, thus the type of neurons activated, is important for AMI implementation. The auditory sensations and/or side effects associated with each site have generally remained stable, indicating minimal movement of the implant over time.

In Figure $2 \mathrm{D}$, we summarize the $\mathrm{T}, \mathrm{C}$, and dynamic range values across patients for the first testing session. Both AMI-1 and AMI-3 have lower $\mathrm{T}$ and $\mathrm{C}$ levels and larger dynamic ranges than AMI-2 (by a factor of $\sim 2-3$ ). The array in AMI-2 is placed outside of the IC (ventral to the dorsal nucleus of the lateral lemniscus) similar to a surface array and likely requires higher current levels to activate neurons farther away.

\section{Sound localization}

The IC receives both monaural and binaural projections from different brainstem nuclei, and it is thought that these projections maintain some segregation up to and within the IC (Cant, 2005; Schofield, 2005). Thus, it is expected that stimulation of different midbrain regions should elicit varying directional percepts. 


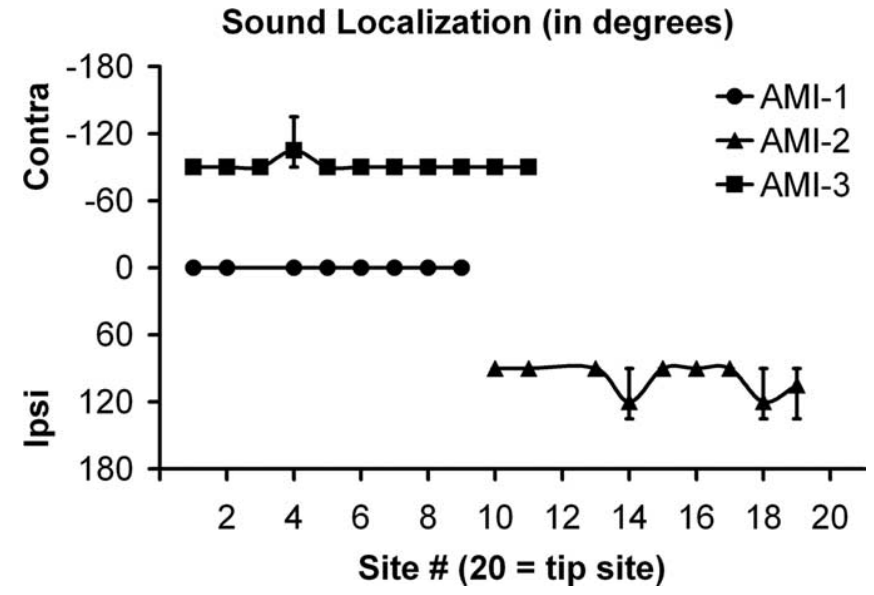

Figure 3. Sound localization (mean and SD; $n=3$ ) for different sites at $\left(\right.$ level. $0^{\circ}$ corresponds to a perceived sound from electrical stimulation of a given site that originates from both directions or in front of the patient, $-90^{\circ}$ to a contralateral (Contra) sound (directly left or right), $90^{\circ}$ to an ipsilateral (Ipsi) sound, and $180^{\circ}$ to a sound coming from behind.

AMI-1, who was implanted in the dorsal IC region, perceived binaural sounds for stimulation of all active sites (Fig. 3). AMI-1 expressed that the loudness percept sometimes varied between sides but not in any obvious manner with stimulation site or level. AMI-2, who was implanted more on the ventral surface of the lateral lemniscus, perceived ipsilateral sounds for all active sites. Usually for the inactive sites but sometimes for the active sites at suprathreshold levels, AMI-2 perceived low vibrations in the contralateral ear that did not appear to be sound sensations. AMI-3, who appears to be implanted within a more caudal and dorsomedial region of the ICC, perceived only contralateral sounds.

\section{Pitch percepts}

One motivation for selecting the IC as a target site for an auditory prosthesis is the well defined tonotopic organization of its central nucleus. This has been shown extensively in animal models (Schreiner and Langner, 1997; Oliver, 2005), and, because of the similarities in the anatomical structure of the IC across mammalian species (Geniec and Morest, 1971), it was inferred that such a functional organization exists within the human ICC. Furthermore, it has been demonstrated previously in a guinea pig model that more localized frequency-specific activation is achievable for ICC stimulation than cochlear stimulation (Lenarz et al., 2006a; Lim and Anderson, 2006). Based on these findings, it was hypothesized that stimulation along the tonotopic gradient of the human ICC would elicit ordered pitch percepts similar to what has been observed for stimulation along the tonotopically organized cochlea. However, this has not yet been the case.

Figure 4 present the results of several pitch ordering tests (using pitch ranking or scaling method as explained in Materials and Methods) performed in both AMI-2 and AMI-3 for different testing sessions. No reliable pitch ordering results were obtained for AMI-1 who had difficulties performing these tests. All the pitch scores from both types of tests were normalized from 0 to 100 to allow for comparison, and the sites were reordered from the lowest average pitch score (across all sessions) to the highest. As is evident from both plots, there is some general shift in pitch scores with the sites reordered. For example, site 16 always had a lower pitch percept than site 17 in AMI-2. Similarly, site 1 always had a lower pitch percept than site 5 in AMI-3. However, the variability across days (even different times on the same day)
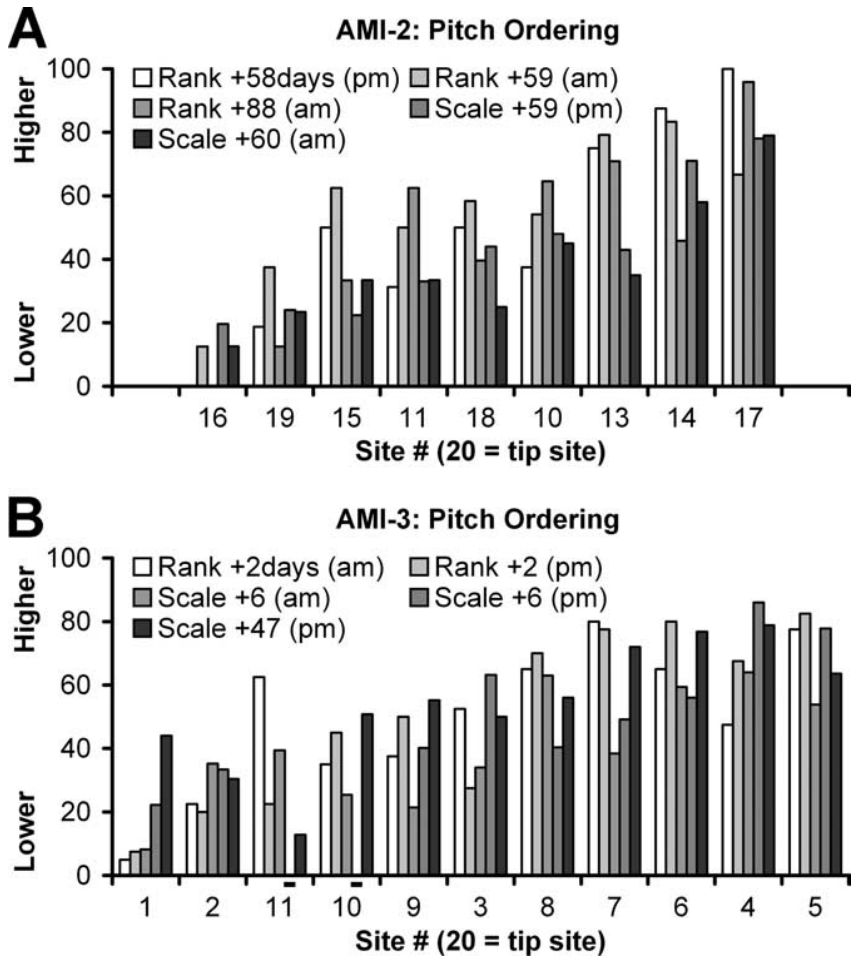

Figure 4. Summary of pitch ordering over time at C level. Pitch ordering using two different methods and normalized to $0-100$ [pitch ranking (Rank) or scaling (Scale); for more details, see Materials and Methods, Psychophysical tests] in which 0 is the lowest pitch and 100 is the highest pitch. The average pitch across testing sessions for each site was calculated and used to reorder the sites in ascending average pitch value. AMI-1 was unable to perform the pitch tests. Days are relative to when the implant was initially turned on; am, morning; pm, evening; -, not tested.

demonstrates the difficulty for these patients in consistently differentiating the pitch between sites. For example, in AMI-3 (Rank $+2 \mathrm{~d}$ ), stimulation of sites 3 and 11 elicited much higher pitch percepts in the morning than in the afternoon. This variability is much greater than what we typically observe for our CI patients. For AMI-2, a lack of a clear systematic spatial pitch organization is not surprising because the array is not aligned along any obvious tonotopic gradient. However, it is still not clear for AMI-3 as to what may be causing the variability in pitch ordering across sessions and the deviation from the low-to-high pitch ordering expected for stimulation of more superficial sites (excluding the most superficial sites, which could be in the external nucleus) to deeper sites within the ICC as predicted from animal models.

Interestingly, all three patients stated that stimulation of their sites generally elicited low pitch sounds. To confirm this, we performed a pitch test with an absolute scale in which different numbers $(0-5)$ corresponded to familiar environmental sounds having different pitches. Data from AMI-2 and AMI-3 are presented in Figure 5 in which stimulation of most of their sites elicited a pitch percept lower than a man's voice, with only a few sites approaching that of a woman's voice. At least in AMI-3, it was expected that some of the deeper sites would elicit higher pitch percepts. AMI-1 had difficulties in scaling the sounds, yet we were able to compare pitch percepts from AMI stimulation to those produced by pure tone stimulation in her right ear (residual hearing up to $1 \mathrm{kHz}$ with thresholds between 30 and $50 \mathrm{~dB} \mathrm{HL}$ ). We found that stimulation of all her sites elicited pitch percepts that were lower than $1 \mathrm{kHz}$. The narrow range of pitches, thus the small differences in pitch between sites, partly explains why the 

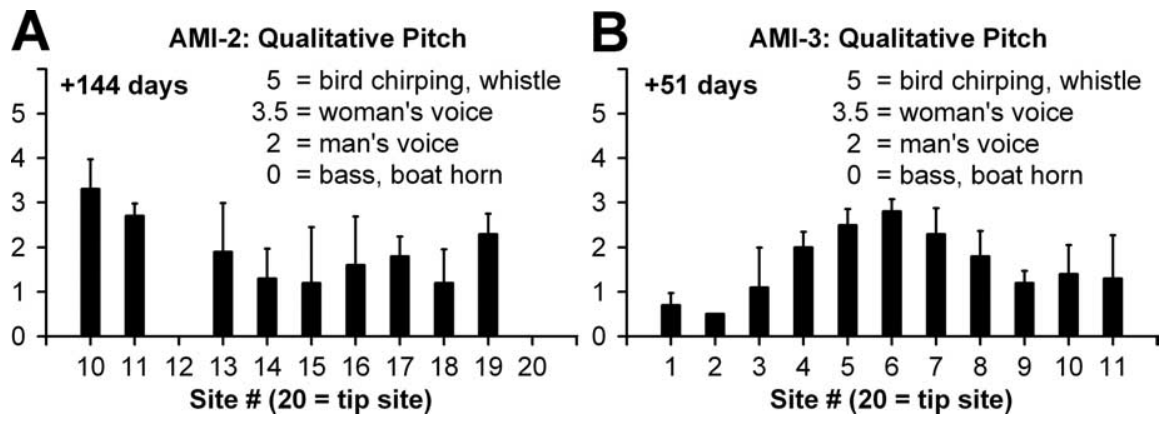

Figure 5. Absolute pitch (mean and SD; $n=5$ ) for each site at C level. The patients were asked to scale the pitch of each stimulated site based on the familiar imagined sounds listed on the plots.
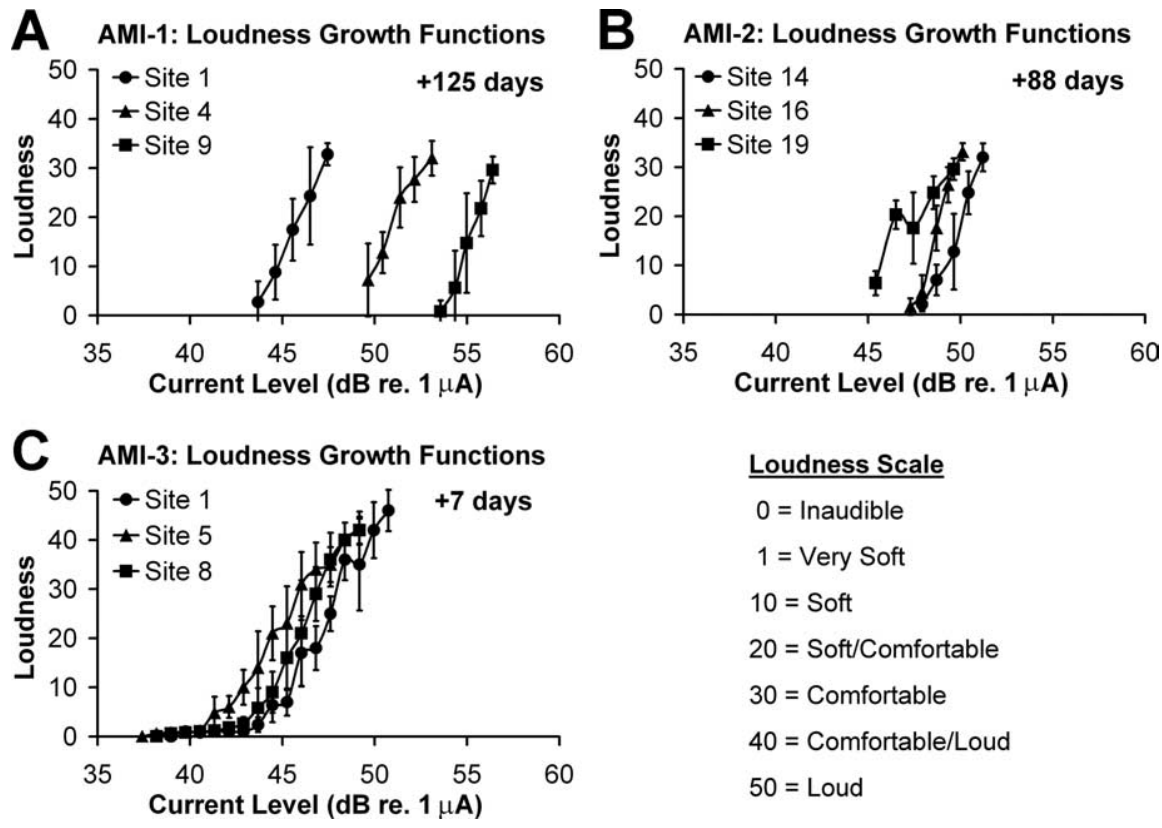

Loudness Scale
$\begin{aligned} 0 & =\text { Inaudible } \\ 1 & =\text { Very Soft } \\ 10 & =\text { Soft } \\ 20 & =\text { Soft/Comfortable } \\ 30 & =\text { Comfortable } \\ 40 & =\text { Comfortable/Loud } \\ 50 & =\text { Loud }\end{aligned}$

Figure 6. Loudness growth functions (mean and SD; $n=5$ ).

patients had difficulty in consistently ordering the pitch percepts across sites. However, this raises another question as to why stimulation of all their sites elicited predominantly low pitches.

\section{Loudness growth functions}

An important feature for an auditory prosthesis is the ability to transmit different loudness contours. Even without precise spectral information, some speech perception is achievable by transmitting only the temporal envelope $(<50 \mathrm{~Hz})$ of the sound input (Shannon et al., 1995). This requires the ability to detect changes in level over time. To assess whether our patients could detect different loudness cues for varying current levels, we obtained loudness growth functions (Fig. 6). All patients exhibited monotonically increasing loudness curves with increasing current levels. The curves for AMI- 1 were measured at $+125 \mathrm{~d}$ when activation levels had already increased substantially. Thus, the curves are generally shifted more to the right than those of the other patients. AMI-3 had curves that were quite similar to each other, more so than those of AMI-2. The curves for AMI-3 also consisted of a shallow tail in which very soft sounds could be heard across a wide range of current levels. AMI-2 had more difficulties detecting subtle changes at lower levels because of tinnitus effects, while AMI-1 was not able to accurately detect very soft sounds. Thus, shallow tail features, if they exist, were not observed in these patients. Overall, these curves demonstrate that different loudness percepts can be systematically achieved via midbrain stimulation using different current levels.

\section{Temporal resolution}

In addition to loudness cues, the ability to follow rapid changes in the temporal structure of the sound input is important for an auditory prosthesis (Shannon et al., 1995). Although the common tests for temporal resolution are amplitude modulation detection and gap detection, we could not perform these tests with our software. Instead, we stimulated a given site with continuous pulse trains that varied in pulse rate and determined the highest rate at which the individual pulses, perceived as buzzing, began to sound continuous (Fig. 7).

For AMI-1 and AMI-3, who were both implanted in the IC, a buzzing percept continued up to $\sim 35-80 \mathrm{pps}$, with a mean $\pm \mathrm{SD}$ of $42 \pm 7$ and $65 \pm 8$ pps, respectively. Interestingly, AMI-2 was able to detect a buzzing percept up to 220 pps (mean $\pm \mathrm{SD}, 180 \pm 17$ ), which was about three times the rate of the other patients.

\section{Speech perception and \\ environmental awareness}

The patients were tested at 6 months for vowels, consonants, numbers, and speech tracking in live voice (Fig. 8). Performance was assessed for lip reading only (V), AMI stimulation only (A), and both conditions (AV).

For the vowel test (Fig. $8 \mathrm{~A}$ ), all three patients achieved high scores for lip reading alone, making it difficult to detect significant lip-reading enhancement with the AMI. However, AMI-2 and AMI-3 obtained 23 and 40\% correct ( $10 \%$ chance level), respectively, with the AMI alone, indicating that they are obtaining some speech information with their implants. For the consonant (Fig. 8B) and number (Fig. 8C) tests, only AMI-3 performed above chance with the AMI alone (12.5 and $10 \%$, respectively). Chance level is $7.7 \%$ for the consonant test and $<1 \%$ for the number test. AMI- 3 also correctly identified parts of each number (e.g., repeated "twenty-two" for the number "twenty-three") 55\% of the time under AMI alone. Furthermore, all three patients exhibited some lip-reading enhancement with the AMI. Figure $8 D$ presents speech tracking results. Under lip reading alone, the patients achieved $\sim 4-10$ words per minute. For both AMI and lip reading, they obtained a lip-reading enhancement of $\sim 2-11$ words per minute (chance level of 0 ).

Speech results in the AMI patients, particularly for AMI-3 who is implanted in the intended target (ICC), are comparable with what are observed in ABI NF2 patients at 6 months. Of 11 ABI NF2 patients tested in our clinic using the same protocols (the same speech therapist tested all the ABI and AMI patients) (Lenarz et al., 2001), only four exceeded the 11 words per minute enhancement achieved by AMI-3. Five ABI patients performed worse than AMI-1 and AMI-2 (less than two to three words per 


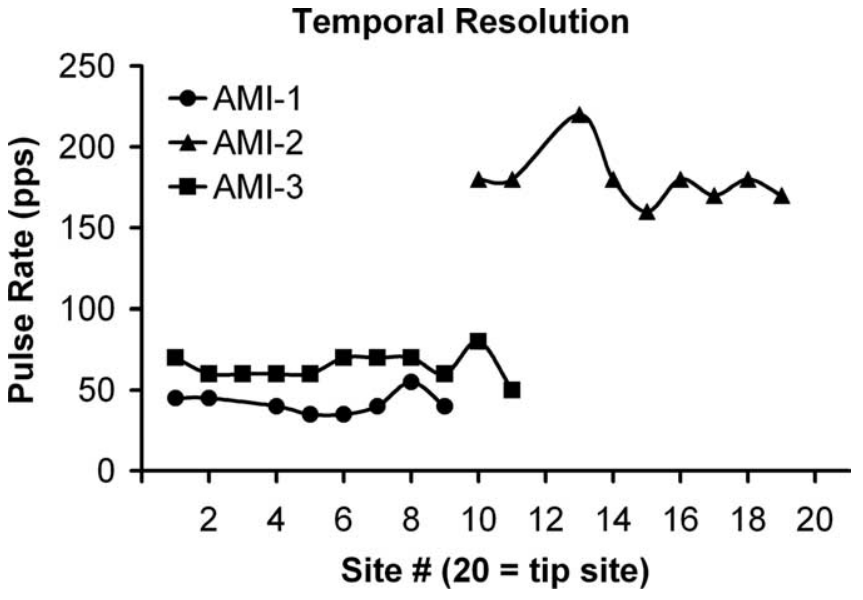

Figure 7. Temporal resolution for different sites at C level. The rate at which the perceived individual pulses began to sound continuous is plotted for each stimulated site (for more details, see Materials and Methods, Psychophysical tests).

minute). All had zero speech tracking scores with the ABI alone. Vowel and consonant scores were also comparable between AMI and $\mathrm{ABI}$ patients, although the latter exhibited a greater range of scores across more patients. Lip-reading enhancement in ABI patients ranged between -4 and $40 \%$, with more than half being below $15 \%$. In $\mathrm{ABI}$ alone mode, vowel scores were $\sim 45 \%$ on average, whereas consonant scores were $\sim 10 \%$, which is consistent with what was observed for AMI-3. Six of the $11 \mathrm{ABI}$ patients did not receive any benefit for $\mathrm{ABI}$ alone in the consonant test. A comparable number test was not performed in the ABI patients.

In addition to speech tests, we also assessed the ability of AMI-2 and AMI-3 to detect and discriminate different instrumental sounds (low frequency: drum, melodica, xylophone, and wooden sticks; high frequency: triangle, ringing bell, jingling bell, and shaker). We randomly played different instruments and asked whether they could detect and identify each one. Both were able to detect all instruments. However, they could only identify the low-frequency instruments. Occasionally, they identified the triangle but generally could not discriminate among the highfrequency instruments.

Overall, the patients are benefiting from their implants as demonstrated by their speech scores and detection of different instruments. More importantly, they have all expressed improvements in their awareness of environmental sounds, such as cars driving by, birds chirping, doors shutting, and the telephone ringing. We have observed the most rapid improvements in AMI-3. The other two patients are improving more slowly because of their dependence on residual hearing and the location of their implants. Before implantation, AMI-3 had difficulties in controlling the volume of her voice. She is now able to speak at a consistent loudness level, has improved the articulation of words, and no longer depends on written conversations.

\section{Discussion}

Functional organization of the human auditory midbrain

One fortunate outcome of our different array placements across patients is that we could assess the effects of various stimuli in specific midbrain regions on perceptual effects, which provide some insight into how the human central auditory system is functionally organized and how we may need to implement an AMI.

\section{Level coding}

AMI sites are in direct contact with surrounding neurons, unlike CI sites; thus, thresholds should be lower as shown in animal studies (Lim and Anderson, 2003, 2006; Lenarz et al., 2006a). However, AMI thresholds (only for AMI-3 whose sites are in the ICC) are $6-12 \mathrm{nC}\left(5-10 \mu \mathrm{C} / \mathrm{cm}^{2}\right)$, and dynamic ranges are 7-9 $\mathrm{dB}$, which are similar to those of the $\mathrm{CI}\left[5-20 \mathrm{nC}\left(\sim 1-5 \mu \mathrm{C} / \mathrm{cm}^{2}\right)\right.$ and $5-10 \mathrm{~dB}$, respectively, using approximately similar stimuli] (Shannon, 1985; Pfingst et al., 1997). It is possible, as shown in guinea pigs (Lim and Anderson, 2007), that stimulation of more caudal and dorsal regions along the ICC laminas, in which the array is located in AMI-3, requires higher current levels for auditory cortical activation than stimulation of more rostral and ventral regions ( $>17 \mathrm{~dB}$ at the extreme edges). However, this then raises the question as to why stimulation of a caudodorsal ICC region would require higher current levels when sites are in close contact to neurons. It is also interesting that loudness growth functions for AMI-3 (Fig. 6C) exhibited long shallow tails in which a very soft sound was heard over a wide range of stimulus levels relative to the dynamic range that then rapidly elevated in loudness. These findings suggest a nonhomogenous organization of excitatory and inhibitory neurons along the isofrequency dimension of the ICC. It is encouraging that all three patients exhibited monotonic loudness functions, indicating that the AMI can systematically elicit different loudness percepts. However, the effects of varying stimuli within these different ICC regions on level coding need to be further investigated to optimize AMI stimulation strategies.

\section{Spectral coding}

Because we only have pitch data for one patient whose array is supposedly aligned along the tonotopic gradient of the ICC, we cannot make any definitive claims as to the tonotopy within the human midbrain until more patients are implanted. However, it is interesting that we did not observe a systematic shift in pitch along the tonotopic gradient of the ICC in AMI-3, and stimulation of different sites in all our patients elicited predominantly low pitch percepts. These findings raise several questions with regards to how we can successfully implement an AMI that will need to be addressed. Are there particular stimuli, both temporally and spatially, required to elicit higher pitch percepts than a simple pulse train at one ICC location (we used pulse rates up to 2400 pps without any obvious increase in pitch from that of 250 pps)? Considering that AMI-3 was deaf for 6 years before implantation, could plastic reorganization of the auditory system result in a loss of high-frequency representation, and, if so, what does this mean for implementing different stimulation strategies across patients with varying deafness conditions? Are high pitch percepts even necessary for speech perception or is it only important to achieve a consistent pitch order? Is the lack of a clear pitch order attributable to location of stimulation along the isofrequency dimension of the ICC, caused by activation of passing fibers with mixed tonotopy, or even associated with differences in auditory midbrain organization in behaving primates?

\section{Temporal coding}

Normal hearing subjects can hear individual noise bursts for repetition rates up to $40 \mathrm{~Hz}$ that then fuse into a continuous percept above $\sim 250 \mathrm{~Hz}$ (Miller and Taylor, 1948). For cochlear and auditory nerve stimulation, patients can hear the pulses of a pulse train perceived as a buzzing for rates up to 250-300 pps (Simmons et al., 1964, 1965; Shannon, 1985). Thus, the brain is wired to allow detection of temporal features of sound with a resolution down to a few milliseconds $(<4 \mathrm{~ms})$ for both normal hearing (Plomp, 1964) and CI (Shannon, 1989) subjects. However, when stimulating within the IC, our patients perceived a continuous 
A Vowel Test

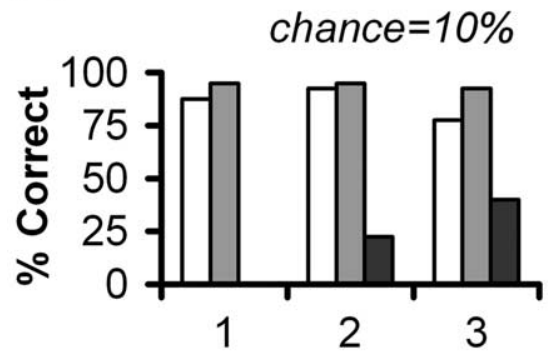

C Number Test

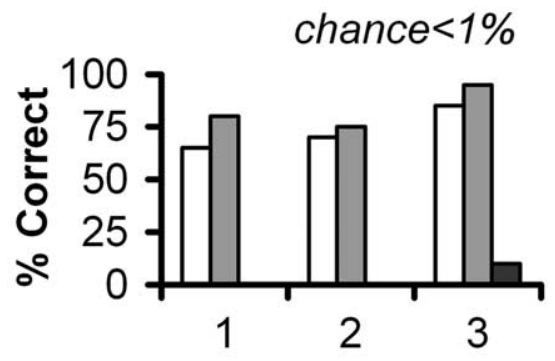

AMI Patient
B Consonant Test

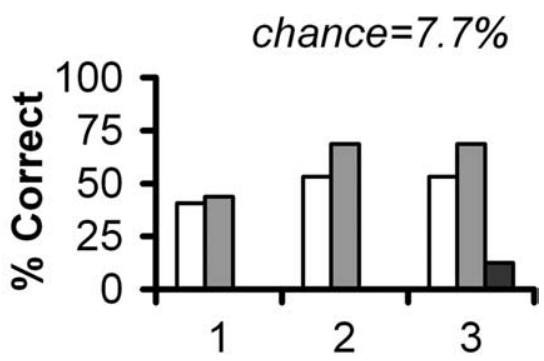

D Speech Tracking

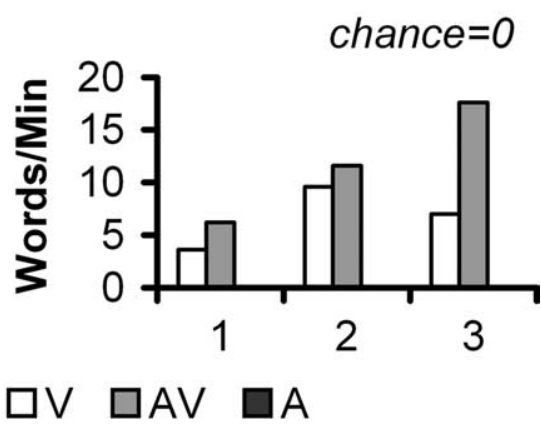

Figure 8. Speech test scores at 6 months. V, Lip reading (visual) alone; AV, lip reading and AMI (audiovisual); A, AMI (audio) alone. Lip-reading enhancement is the difference between $A V$ and $V$. A value of 0 means the patient could not perform the test.

stimuli for pulse rates above 80 pps, with most cases at $\sim 50$ pps, which corresponds to a resolution of $\sim 20 \mathrm{~ms}$.

Animal studies have shown that auditory nerve fibers can synchronize to high-rate (exceeding $1 \mathrm{kHz}$ ) acoustic (Johnson, 1980; Joris and Yin, 1992) and cochlear (Hartmann and Klinke, 1989; Shepherd and Javel, 1997) stimulation, whereas neurons higher along the auditory pathway are less able to follow high-rate stimulation (Phillips et al., 1989; Lu and Wang, 2000; Snyder et al., 2000). This degradation in temporal synchronization is hypothesized to be compensated for by spatial coding (based on spike rate) of temporal features (Schreiner and Langner, 1988; Lu et al., 2001). The fact that AMI-2, who was implanted at the level of the lateral lemniscus, was able to detect a buzzing percept beyond 200 pps that was almost three times greater than the rates of the other patients implanted into the IC is consistent with this hypothesis. However, it is also possible that the sites for AMI-1 and AMI-3 are just located in regions of low temporal resolution. In guinea pigs, stimulation of more caudal and dorsal regions along an ICC lamina, in which AMI-3 is implanted, elicits auditory cortical activity with longer latencies and greater spiking jitter (Lim and Anderson, 2007). Both explanations emphasize the need for appropriate placement and/or more complex spatial stimuli within the ICC to achieve enhanced coding of temporal features.

\section{Sound localization}

Stimulation of all active sites (spanning 1.7-1.9 mm) elicited the same directional percept in each patient. AMI-1 obtained all bilateral percepts, which could be caused by activation of monaural and binaural neurons throughout the dorsal and commissure of the IC (Malmierca et al., 2005; Saldana and Merchan, 2005). AMI-2 and AMI-3 obtained all ipsilateral and contralateral percepts, respectively, suggesting some segregation of ipsilateral and contralateral pathways ascending into and within the IC. In animals, it has been shown that different brainstem nuclei associated with monaural or binaural features project in a somewhat segregated pattern to different regions of the ICC (Roth et al., 1978; Loftus et al., 2004; Cant and Benson, 2006) and even up to primary auditory cortex (Andersen et al., 1980; Middlebrooks and Zook, 1983; Rutkowski et al., 2000). For example, in cats (frequency regions $>5$ $\mathrm{kHz}$ ), neurons from the contralateral dorsal cochlear nucleus project throughout an ICC lamina, whereas neurons from the lateral superior olive project bilaterally only to the ventrolateral portion (Loftus et al., 2004). In other words, it is more likely to find neurons excited solely by contralateral sounds in the dorsomedial region of the ICC. This could explain why we observed only contralateral percepts for AMI-3. The findings for AMI-2 further suggest that a segregated group (or at least a predominance) of ipsilaterally excited projections to the IC exist within the ventral portion of the lateral lemniscus in humans. Considering that the medial olivary nucleus is enlarged whereas the lateral olivary nucleus is reduced in humans compared with animals (Moore, 1987) and only a small proportion of ipsilaterally excited pathways to the IC appear to originate from the cochlear nucleus and periolivary region, this segregated region may correspond predominantly to fibers from the medial superior olive (Nordeen et al., 1983; Oliver, 1987; Masterton et al., 1992; Oliver et al., 1995; Schofield, 2005). This is interesting in that projections from the brainstem nuclei to the IC tend to be more excited contralaterally based on animal studies, yet stimulation of an $\sim 2 \mathrm{~mm}$ midbrain region elicited only ipsilateral percepts. Most of the ipsilaterally excited pathways consist of neurons sensitive to low-frequency sounds, which would explain the dominance of low pitches perceived by AMI-2. Overall, our results support the animal-derived hypothesis of segregated monaural/binaural pathways within the central auditory system and demonstrate the importance of stimulation location within the midbrain for achieving different sound localization percepts.

\section{The $\mathrm{AMI}$ as an alternative to the $\mathrm{CI}$ or $\mathrm{ABI}$}

If the patient has an implantable cochlea and functional auditory nerve, then the preferred intervention is the CI. If the cochlea is obliterated or the auditory nerve is not viable, then the AMI is an alternative to the ABI. The AMI offers the crucial advantage over the $\mathrm{ABI}$ in that it can be surgically implanted under direct visual exposure of the target region, without brain distortions caused by tumors in NF2 patients, and with less risks of damaging critical brainstem structures and cranial nerves. Our results demonstrate that the AMI is safe for human use and provides different loudness, pitch, temporal, and directional percepts, features that have shown to be important for speech perception (Pfingst et al., 1983; Shannon et al., 1995; Nelson et al., 1996; Friesen et al., 2001) and more complex sound processing (Smith et al., 2002; Shannon et al., 2004; Kidd et al., 2005). Furthermore, the AMI can provide performance levels at least comparable with the ABI in NF2 patients, particularly when stimulating the ICC.

Although the improvements in hearing performance have been moderate compared with what CI patients can achieve 
within the same time period, we expect the patients to improve with training and more appropriate stimuli than those designed for the cochlea. The questions remain as to what are "appropriate" stimuli and if simultaneous stimulation across different frequency and isofrequency regions within the ICC and even other subregions of the IC are required to elicit the desired percepts. At least based on animal studies, we believe that stimulation of more rostral and ventrolateral regions within the ICC may provide additional improvements in performance (Lim and Anderson, 2007), and this may be sufficient to restore open-set speech perception. However, if we are going to take advantage of the enormous amount of information passing through the IC, which receives almost all projections from lower brainstem nuclei (Casseday et al., 2002), and considering that we observed different perceptual effects depending on stimulation location as discussed above, then we will likely need to develop a threedimensional array that sufficiently spans and activates the IC. These are questions we are currently investigating with the hope that the AMI will serve as a successful hearing alternative for those who cannot benefit from CIs.

\section{References}

Adams JS, Hasenstab MS, Pippin GW, Sismanis A (2004) Telephone use and understanding in patients with cochlear implants. Ear Nose Throat J 83:96, 99-100, 102-103.

Andersen RA, Roth GL, Aitkin LM, Merzenich MM (1980) The efferent projections of the central nucleus and the pericentral nucleus of the inferior colliculus in the cat. J Comp Neurol 194:649-662.

Brackmann DE, Hitselberger WE, Nelson RA, Moore J, Waring MD, Portillo F, Shannon RV, Telischi FF (1993) Auditory brainstem implant: I. Issues in surgical implantation. Otolaryngol Head Neck Surg 108:624-633.

Cant NB (2005) Projections from the cochlear nuclear complex to the inferior colliculus. In: The inferior colliculus (Winer JA, Schreiner CE, eds), pp 115-131. New York: Springer Science+Business Media.

Cant NB, Benson CG (2006) Organization of the inferior colliculus of the gerbil (Meriones unguiculatus): differences in distribution of projections from the cochlear nuclei and the superior olivary complex. J Comp Neurol 495:511-528.

Casseday JH, Fremouw T, Covey E (2002) The inferior colliculus: a hub for the central auditory system. In: Springer handbook of auditory research: integrative functions in the mammalian auditory pathway, Vol 15 (Oertel D, Fay RR, Popper AN, eds), pp 238-318. New York: Springer.

Colletti V, Shannon RV (2005) Open set speech perception with auditory brainstem implant? Laryngoscope 115:1974-1978.

De Filippo CL, Scott BL (1978) A method for training and evaluating the reception of ongoing speech. J Acoust Soc Am 63:1186-1192.

Evans DG, Huson SM, Donnai D, Neary W, Blair V, Teare D, Newton V, Strachan T, Ramsden R, Harris R (1992) A genetic study of type 2 neurofibromatosis in the United Kingdom. I. Prevalence, mutation rate, fitness, and confirmation of maternal transmission effect on severity. J Med Genet 29:841-846.

Friesen LM, Shannon RV, Baskent D, Wang X (2001) Speech recognition in noise as a function of the number of spectral channels: comparison of acoustic hearing and cochlear implants. J Acoust Soc Am 110:1150-1163.

Geniec P, Morest DK (1971) The neuronal architecture of the human posterior colliculus. A study with the Golgi method. Acta Otolaryngol Suppl 295:1-33.

Hartmann R, Klinke R (1989) Response characteristics of nerve fibers to patterned electrical stimulation. In: Cochlear implants: models of the electrically stimulated ear (Miller JM, Spelman FA, eds), pp 135-160. New York: Springer.

Johnson DH (1980) The relationship between spike rate and synchrony in responses of auditory-nerve fibers to single tones. J Acoust Soc Am 68:1115-1122.

Joris PX, Yin TC (1992) Responses to amplitude-modulated tones in the auditory nerve of the cat. J Acoust Soc Am 91:215-232.

Kidd Jr G, Arbogast TL, Mason CR, Gallun FJ (2005) The advantage of knowing where to listen. J Acoust Soc Am 118:3804-3815.

Kretschmann HJ, Weinrich W (1992) Cranial neuroimaging and clinical neuroanatomy: magnetic resonance imaging and computed tomography, Ed 2. New York: Thieme Medical Publishers.

Lenarz T, Moshrefi M, Matthies C, Frohne C, Lesinski-Schiedat A, Illg A, Rost U, Battmer RD, Samii M (2001) Auditory brainstem implant: part I. Auditory performance and its evolution over time. Otol Neurotol 22:823-833.

Lenarz M, Lim HH, Patrick JF, Anderson DJ, Lenarz T (2006a) Electrophysiological validation of a human prototype auditory midbrain implant in a guinea pig model. J Assoc Res Otolaryngol 7:383-398.

Lenarz T, Lim HH, Reuter G, Patrick JF, Lenarz M (2006b) The auditory midbrain implant: a new auditory prosthesis for neural deafness-concept and device description. Otol Neurotol 27:840-845.

Lim HH, Anderson DJ (2003) Feasibility experiments for the development of a midbrain auditory prosthesis. In: Proceedings of the First International IEEE EMBS Conference of Neural Engineering. March, Capri Island, Italy.

Lim HH, Anderson DJ (2006) Auditory cortical responses to electrical stimulation of the inferior colliculus: implications for an auditory midbrain implant. J Neurophysiol 96:975-988.

Lim HH, Anderson DJ (2007) Spatially distinct functional output regions within the central nucleus of the inferior colliculus: implications for an auditory midbrain implant. J Neurosci 27:8733-8743.

Loftus WC, Bishop DC, Saint Marie RL, Oliver DL (2004) Organization of binaural excitatory and inhibitory inputs to the inferior colliculus from the superior olive. J Comp Neurol 472:330-344.

Lu T, Wang X (2000) Temporal discharge patterns evoked by rapid sequences of wide- and narrowband clicks in the primary auditory cortex of cat. J Neurophysiol 84:236-246.

Lu T, Liang L, Wang X (2001) Temporal and rate representations of timevarying signals in the auditory cortex of awake primates. Nat Neurosci 4:1131-1138

Malmierca MS, Hernandez O, Rees A (2005) Intercollicular commissural projections modulate neuronal responses in the inferior colliculus. Eur J Neurosci 21:2701-2710.

Masterton RB, Granger EM, Glendenning KK (1992) Psychoacoustical contribution of each lateral lemniscus. Hear Res 63:57-70.

Middlebrooks JC, Zook JM (1983) Intrinsic organization of the cat's medial geniculate body identified by projections to binaural response-specific bands in the primary auditory cortex. J Neurosci 3:203-224.

Miller GA, Taylor WG (1948) The perception of repeated bursts of noise. J Acoust Soc Am 20:171-182.

Moore JK (1987) The human auditory brain stem: a comparative view. Hear Res 29:1-32.

Nelson DA, Schmitz JL, Donaldson GS, Viemeister NF, Javel E (1996) Intensity discrimination as a function of stimulus level with electric stimulation. J Acoust Soc Am 100:2393-2414.

Nordeen KW, Killackey HP, Kitzes LM (1983) Ascending auditory projections to the inferior colliculus in the adult gerbil, Meriones unguiculatus. J Comp Neurol 214:131-143.

Oliver DL (1987) Projections to the inferior colliculus from the anteroventral cochlear nucleus in the cat: possible substrates for binaural interaction. J Comp Neurol 264:24-46.

Oliver DL (2005) Neuronal organization in the inferior colliculus. In: The inferior colliculus (Winer JA, Schreiner CE, eds), pp 69-114. New York: Springer Science+Business Media.

Oliver DL, Beckius GE, Shneiderman A (1995) Axonal projections from the lateral and medial superior olive to the inferior colliculus of the cat: a study using electron microscopic autoradiography. J Comp Neurol 360:17-32.

Otto SR, Brackmann DE, Hitselberger WE, Shannon RV, Kuchta J (2002) Multichannel auditory brainstem implant: update on performance in 61 patients. J Neurosurg 96:1063-1071.

Patrick JF, Busby PA, Gibson PJ (2006) The development of the nucleus freedom cochlear implant system. Trends Amplif 10:175-200.

Perez-Gonzalez D, Malmierca MS, Covey E (2005) Novelty detector neurons in the mammalian auditory midbrain. Eur J Neurosci 22:2879-2885.

Pfingst BE, Burnett PA, Sutton D (1983) Intensity discrimination with cochlear implants. J Acoust Soc Am 73:1283-1292.

Pfingst BE, Zwolan TA, Holloway LA (1997) Effects of stimulus configuration on psychophysical operating levels and on speech recognition with cochlear implants. Hear Res 112:247-260. 
Phillips DP, Hall SE, Hollett JL (1989) Repetition rate and signal level effects on neuronal responses to brief tone pulses in cat auditory cortex. J Acoust Soc Am 85:2537-2549.

Plomp R (1964) Rate of decay of auditory sensation. J Acoust Soc Am 36:277-282.

Rost U, Strauss-Schier A (1998) Rehabilitations und Testkonzept bei Erwachsenen. In: Cochlea-Implantat: Ein praktischer Leitfaden fur die Versorgung von Kindern und Erwachsenen (Lenarz T, ed), pp 136-145. Stuttgart, Germany: Springer.

Roth GL, Aitkin LM, Andersen RA, Merzenich MM (1978) Some features of the spatial organization of the central nucleus of the inferior colliculus of the cat. J Comp Neurol 182:661-680.

Rutkowski RG, Wallace MN, Shackleton TM, Palmer AR (2000) Organisation of binaural interactions in the primary and dorsocaudal fields of the guinea pig auditory cortex. Hear Res 145:177-189.

Saldana E, Merchan MA (2005) Intrinsic and commissural connections of the inferior colliculus. In: The inferior colliculus (Winer JA, Schreiner CE, eds), pp 155-181. New York: Springer Science+Business Media.

Samii A, Lenarz M, Majdani O, Lim HH, Samii M, Lenarz T (2007) Auditory midbrain implant: a combined approach for vestibular schwannoma surgery and device implantation. Otol Neurotol 28:31-38.

Schofield BR (2005) Superior olivary complex and lateral lemniscal connections of the auditory midbrain. In: The inferior colliculus (Winer JA, Schreiner CE, eds), pp 132-154. New York: Springer Science+Business Media.

Schreiner CE, Langner G (1988) Periodicity coding in the inferior colliculus of the cat. II. Topographical organization. J Neurophysiol 60:1823-1840.

Schreiner CE, Langner G (1997) Laminar fine structure of frequency organization in auditory midbrain. Nature 388:383-386.
Shannon RV (1985) Threshold and loudness functions for pulsatile stimulation of cochlear implants. Hear Res 18:135-143.

Shannon RV (1989) Detection of gaps in sinusoids and pulse trains by patients with cochlear implants. J Acoust Soc Am 85:2587-2592.

Shannon RV, Zeng FG, Kamath V, Wygonski J, Ekelid M (1995) Speech recognition with primarily temporal cues. Science 270:303-304.

Shannon RV, Fu QJ, Galvin III J (2004) The number of spectral channels required for speech recognition depends on the difficulty of the listening situation. Acta Otolaryngol Suppl 50-54.

Shepherd RK, Javel E (1997) Electrical stimulation of the auditory nerve. I. Correlation of physiological responses with cochlear status. Hear Res 108:112-144.

Simmons FB, Mongeon CJ, Lewis WR, Huntington DA (1964) Electrical stimulation of acoustical nerve and inferior colliculus. Arch Otolaryngol 79:559-568.

Simmons FB, Epley JM, Lummis RC, Guttman N, Frishkopf LS, Harmon LD, Zwicker E (1965) Auditory nerve: electrical stimulation in man. Science 148:104-106.

Smith ZM, Delgutte B, Oxenham AJ (2002) Chimaeric sounds reveal dichotomies in auditory perception. Nature 416:87-90.

Snyder RL, Vollmer M, Moore CM, Rebscher SJ, Leake PA, Beitel RE (2000) Responses of inferior colliculus neurons to amplitudemodulated intracochlear electrical pulses in deaf cats. J Neurophysiol $84: 166-183$

Strauss-Schier A, Battmer RD, Rost U, Allum-Mecklenburg DJ, Lenarz T (1995) Speech-tracking results for adults. Ann Otol Rhinol Laryngol Suppl 166:88-91.

Winer JA (2005) Three systems of descending projections to the inferior colliculus. In: The inferior colliculus (Winer JA, Schreiner CE, eds), pp 231-247. New York: Springer Science+Business Media. 